\title{
Curative lobectomy in a patient with pulmonary arteriovenous fistula
}

\author{
Filip Franciszek Karuga, Zuzanna Żychowicz, Magdalena Rogut, Agata Gabryelska, Piotr Białasiewicz \\ Department of Sleep Medicine and Metabolic Disorders, Medical University of Łódź, Łódź, Poland
}

A 26-year-old Caucasian male was referred to the Sleep and Respiratory Disorders Centre with a past medical history of polycythemia and hypoxemia with chronic respiratory alkalosis. The patient complained of feeling dyspneic on exertion. On admission, the patient had a normal pulse $(82 / \mathrm{min})$ and was normotensive $(115 / 75 \mathrm{~mm} \mathrm{Hg})$ with signs of peripheral cyanosis and digital clubbing. Normal vesicular sounds were heard on auscultation.

Prior to referral, the patient was admitted to a cardiac surgery clinic due to low exercise tolerance. Laboratory tests revealed hypoxemia with chronic respiratory alkalosis $\left(\mathrm{pH}=7.45, \mathrm{pO}_{2}=45 \mathrm{~mm} \mathrm{Hg}, \mathrm{pCO}_{2}=26\right.$ $\mathrm{mm} \mathrm{Hg}, \mathrm{HCO}_{3}=17.9 \mathrm{mM}, \mathrm{SpO}_{2}=84 \%$ ) and polycythemia (Hb $19.2 \mathrm{~g} / \mathrm{dL}$; Hct 60.8\%). An ECG showed no significant abnormalities. In echocardiography, a type 2 minor atrial septal defect (ASD) with a left-to-right shunt was found, as well as mitral valve prolapse with a preserved ejection fraction of $60 \%$. Right-heart catheterization was performed and revealed a cardiac output of $4.74 \mathrm{~L} / \mathrm{min}$ and a cardiac index of $2.67 \mathrm{~L} / \mathrm{min} / \mathrm{m}^{2}$ with a pulmonary-to-systemic flow ratio of 1.16:1.00. Aortography showed no changes in the aortic arch and descending aorta, and no vascular malformations. Chest radiography did not show any anomalies. The patient was discharged from the hospital with a diagnosis of minor ASD left-to-right shunt that, apparently, did not explain his complaints or abnormal test results. Fortunately, lung scintigraphy was suggested on discharge. Curiously, upon a subsequent visit to his family doctor, the patient was ordered to exercise regularly to improve his fitness because deconditioning was suggested to be the culprit of his symptoms. However, the patient's repeated efforts to exercise resulted in a loss of consciousness.

Following these events, pulmonary function tests were performed at the Sleep and Respiratory Disorders Centre. In body plethysmography, lung static volumes were within normal limits, but carbon monoxide diffusion capacity $\left(\mathrm{D}_{\mathrm{L}, \mathrm{CO}}\right)$ was decreased (Table 1$)$.

Later, the patient was readmitted to the hospital in order to undergo lung scintigraphy. It revealed a lack of perfusion in the $10^{\text {th }}$ segment of the right lung. Chest radiography in a PA projection revealed a semi-circular shade at the Th12-L1 level in the right paravertebral line with dimensions of $4.5 \times 3.0 \mathrm{~cm}$ which were not visible in the lateral projection. Based on the gathered evidence, a pulmonary arteriovenous fistula (PAVF) was suspected and the patient was referred to a thoracic surgery clinic where a decision was made to perform right anterolateral thoracotomy and right lower lobectomy. Prior to surgery, laboratory tests were ordered and confirmed polycythemia and hypoxemia with chronic respiratory alkalosis (Table 1). The surgery was uneventful.

One month after the surgery, a normalization of arterial blood gas (ABG) parameters was noted. Three months later, a follow-up $\mathrm{D}_{\mathrm{LCO}}$ was performed and the results showed a significant improvement. Body plethysmography revealed decreased static lung volumes, which was expected (Table 1).

PAVF is a rare disorder characterized by the presence of an abnormal, non-capillary vessel connecting pulmonary arteries and veins. Over $80 \%$ of PAVF cases are reported to be congenital [1], and $70 \%$ of all cases are associated with hereditary hemorrhagic telangiectasia [2]. Secondary PAVF can be brought on by various factors such as trauma, infection, systemic amyloidosis, or mitral stenosis. Reported incidence of PAVF is 2-3 per 100000 [1]. More than half of all patients with PAVF are asymptomatic and the condition is discovered during routine chest radiography. If signs and symptoms are present, they are usually nonspecific and vary from subtle to severe. They include dyspnea, hemoptysis, polycythemia, cyanosis, and digital clubbing, among others [3]. However, the most serious complication of PAVF is paradoxical embolization and as such, even the treatment of small fistulas is warranted [4]. Pulmonary angiography is considered to be the gold standard for the diagnosis of PAVF [5]. Treatment includes embolization (less invasive) or surgery (lower recurrence rate) [2].

Isolated PAVF poses a diagnostic challenge because, as was the case with our patient, their family history of arteriovenous malformations and/or telangiectasias can be negative. A right-to-left cardiac shunt should be

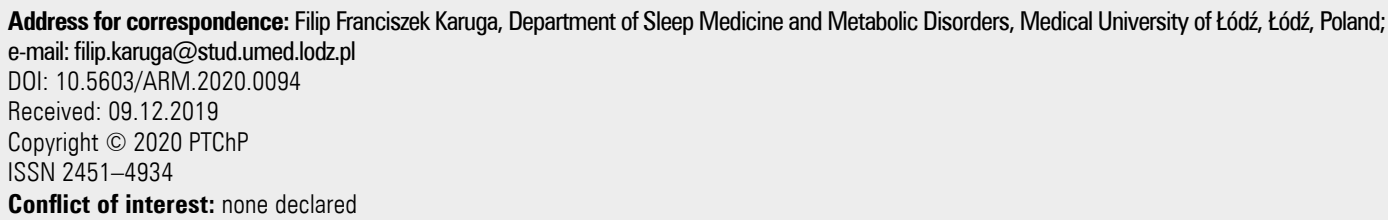


addressed first as it is more prevalent. If this pathology is ruled out, PAVF should be considered. The diagnosis in our patient was based on indirect evidence including chest X-rays, pulmonary scintigraphy, and a lack of perfusion in one of the lung segments. All of these can be attributed to the phenomenon of perfusion stealing by the fistula. Paradoxically, lobectomy resulting in lower lung volumes markedly improved gas exchange and reversed chronic hypoxemia and polycythemia (Table 1).

Table 1. Comparison of ABG, $D_{L, c 0}$ and bodyplethysmography parameters before and after the surgery (lobectomy)

\begin{tabular}{|c|c|c|}
\hline Parameter & Before surgery & After surgery \\
\hline \multicolumn{3}{|l|}{ ABG } \\
\hline $\mathrm{pH}$ & 7.42 & 7.43 \\
\hline $\mathrm{pO}_{2}[\mathrm{~mm} \mathrm{Hg}]$ & 40 & 69 \\
\hline $\mathrm{pCO}{ }_{2}[\mathrm{~mm} \mathrm{Hg}]$ & 26 & 36 \\
\hline $\mathrm{HCO}_{3}[\mathrm{mM}]$ & 16.9 & 23.8 \\
\hline $\mathrm{SpO}_{2}[\%]$ & 77 & 94 \\
\hline \multicolumn{3}{|l|}{$D_{L, C 0}-S B$} \\
\hline 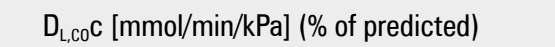 & $7.03(60)$ & $7.92(68)$ \\
\hline VA [L] (\% of predicted) & $5.88(87)$ & $5.37(80)$ \\
\hline $\mathrm{D}_{\mathrm{L}, \mathrm{co}} \mathrm{C} / \mathrm{VA}[\mathrm{mmol} / \mathrm{min} / \mathrm{kPa} / \mathrm{L}]$ (\% of predicted) & $1.20(71)$ & $1.48(87)$ \\
\hline $\mathrm{Hb}[\mathrm{g} / 100 \mathrm{ml}]$ & 19.60 & 15.15 \\
\hline RV-He [L] (\% of predicted) & $1.09(67)$ & $1.51(92)$ \\
\hline TLC-He [L] (\% of predicted) & $6.01(87)$ & $5.50(80)$ \\
\hline \multicolumn{3}{|l|}{ Bodyplethysmography } \\
\hline RV [L] (\% of predicted) & $1.63(100)$ & $1.55(95)$ \\
\hline TLC [L] (\% of predicted) & $6.90(100)$ & $5.84(85)$ \\
\hline
\end{tabular}

ABG was determined in arterialized blood sample. ABG — arterial blood gas; $\mathrm{D}_{\mathrm{L}, \mathrm{co}}-$ transfer factor for carbon monoxide; $\mathrm{D}_{\mathrm{L}, \mathrm{co}}-\mathrm{SB}$ - single breath, carbon monoxide diffusing capacity of the lung; $\mathrm{D}_{\mathrm{L}, \mathrm{co}} \mathrm{C}-\mathrm{D}_{\mathrm{L}, \mathrm{co}}$ corrected for $\mathrm{Hb}$; VA - alveolar volume; $\mathrm{D}_{\mathrm{L}, \mathrm{co}} \mathrm{C} / \mathrm{NA}-\mathrm{D}_{\mathrm{L}, \mathrm{co}}$ corrected for $\mathrm{Hb}$ and VA (Krogh Factor); RV-He

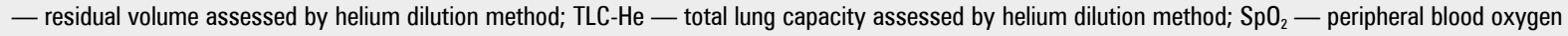
hemoglobin saturation

\section{References:}

1. Pick A, Deschamps C, Stanson AW. Pulmonary arteriovenous fistula: presentation, diagnosis, and treatment. World J Surg. 1999; 23(11): 1118-1122, doi: 10.1007/s002689900634, indexed in Pubmed: 10501873.

2. Gossage JR, Kanj G. Pulmonary arteriovenous malformations. A state of the art review. Am J Respir Crit Care Med. 1998; 158(2): 643-661, doi: 10.1164/ajrccm.158.2.9711041, indexed in Pubmed: 9700146.

3. Burke CM, Safai C, Nelson DP, et al. Pulmonary arteriovenous malformations: a critical update. Am Rev Respir Dis. 1986; 134(2): 334-339, doi: 10.1164/arrd.1986.134.2.334, indexed in Pubmed: 3527008.

4. Wang CC, Wang JK, Hsu JY, et al. Isolated pulmonary arteriovenous fistula in a patient with recurrent stroke. Acta Cardiol Sin. 2013; 29(1): 107-109.

5. Hodgson CH, Kaye RL. Pulmonary arteriovenous fistula and hereditary hemorrhagic telangiectasia: a review and report of 35 cases of fistula. Dis Chest. 1963; 43: 449-455, doi: 10.1378/chest.43.5.449, indexed in Pubmed: 13963797. 